\title{
Natural Incidence of Aflatoxins and Ochratoxin A Nuts Collected from Local Market in Tripoli
}

\author{
N. Essawet ${ }^{1}$, H. Abushahma ${ }^{2}$, S. Inbaia ${ }^{*}$, A. Najii ${ }^{1}$ and H.A. Amra ${ }^{3}$ \\ ${ }^{1}$ Azzaytuna University-Libya \\ ${ }^{2}$ Higher Institute of Agriculture Techniques, Al-Ghiran-Libya \\ ${ }^{3}$ National Research Center, Egypt \\ *Corresponding author
}

\section{A B S T R A C T}

\begin{tabular}{|l|}
\hline Ke y w or d s \\
Mycotoxin, \\
Aflatoxins, \\
Ochratoxin A, \\
Aspergillus.
\end{tabular}

\begin{abstract}
Aflatoxins and ochratoxin A are mycotoxins produced by fungi belonging to the Aspergillus and Penicillium genera. The present study was carried out to study the natural occurrence of aflatoxins (AFS) and ochratoxinA (OA) in 90 nut samples collected from Tripoli, Libya during 2013 were determined by using a high-performance liquid chromatography technique. Aflatoxins B1, B2, G1 and G2, in the local market in Tripoli Libya during summer, 2013. Natural occurrence of aflatoxin B1, B2, G1 and G2 in almonds, Br. almonds, hazelnuts, cashews, walnuts and peanuts samples collected from local market in Tripoli. The percentages of positive samples with aflatoxins were 33.3, 40.0, 20.0, 13.3, 26.6 and 53.3\% for almonds, Brazilian almonds, hazelunts, cashews, walnuts and peanuts, respectively. The concentrations of aflatoxin B1 were ranged between $(0.9-5.3,1.4-7.8,1.2-5.4,2.1-3.4,1.6-7.8$ and $2.4-10.9 \mu \mathrm{g} / \mathrm{kg}$ ) for almonds, Brazilian almonds, hazelunts, cashews, walnuts and peanuts, respectively. Aflatoxin B2 were found in Brazilian almonds ranged from $(2.2-3.5 \mu \mathrm{g} / \mathrm{kg})$ and in peanut (7.6-8.4 $\mu \mathrm{g} / \mathrm{kg}$ ). These results indicate the contamination of nuts with aflatoxins B1 and B2 were in various concentrations, this difference depends on type of nuts and environmental conditions, as well as the availability of nutrients to the fungus. The percentages of nut samples (almonds, Brazilian almonds, hazelunts, cashews, walnuts and peanuts) were contaminated with ochratoxin A 26.6, 33.3, 13.3, 20.0, 13.3 and 33.3\%, respectively, also the concentrations were ranged between (3.5-5.0,1.5- 2.2, $1.2-3.7,1.3-2.5$, and 4.0-6.5 $\mu \mathrm{g} / \mathrm{kg}$ ) for Brazilian almonds, hazelunts, cashews, walnuts and peanuts, respectively. However almonds free of ochratoxin A. The highest concentration found in peanut samples $(6.5 \mu \mathrm{g} / \mathrm{kg})$. The difference concentration of AFS or OA may be depends on type of nuts and environmental conditions, as well as the availability of nutrients to the fungus.
\end{abstract}

\section{Introduction}

Mycotoxin contamination is a worldwide food safety problem that has attracted global attention due to significant losses associated with its impact on human and animal health and consequently, national and economic implications (Makun et al., 2009).
Dry fruits including tree nuts are highly susceptible to fungal attacks both while in the field and during storage which may result in production of mycotoxins in them. Most of these toxins are thermostable at high temperatures (Kabak, 2009) and can, 
therefore, contaminate processed foods and enter the human food chain through derived foods. The mycotoxin of prime concern, due to their toxicity and prevalence, are aflatoxins (AFs) and ochratoxin A (OTA).

AFs are found as contaminants in various agricultural commodities.

The commodities with the highest risk of AFs contamination include corn, peanut, cottonseed, Brazilian nuts, pistachio nut, fig, spice and copra (Pittet, 1998).

Aflatoxins are difuranocoumarin derivatives synthesized by polyketide pathway by various strains of Aspergillus, mainly A. flavus and A. parasiticus. Besides this, several other species of Aspergillus belonging to section Flavi, Ochraceorosei and Nidulantes have been claimed to produce aflatoxins. Aflatoxins have immunotoxic, mutagenic and carcinogenic effects (Moss, 1998) and have been classified as group 1 carcinogen by the International Agency for Research on Cancer (IARC) (IARC, 1993). Occurrence of AFs contamination on several agricultural products such as maize, wheat, rice, spices, dried fruits and nuts has been reported worldwide (Grajewski et al., 2012; Nguyen and Ryu, 2014).

Ochratoxin A (OTA) is a ubiquitous mycotoxin produced by several fungal species belonging to the genera Aspergillus (e.g. Aspergillus ochraceus) and Penicillium (e.g. Penicillium verrucosum) (Alvarez et al., 2004). OTA is a potential nephrotoxin with carcinogenic potential and hepatotoxic and teratogenic mycotoxin in animal species and it is classified by the IARC as a possible human carcinogen of Group 2B (IARC, 1993). The toxin has also been found in human sera from people. Living in areas where Balkan endemic nephropathy occurs, and it is suggested to be a possible determinant of this fatal human disease (Hult et al., 1982). It has also been extensively documented as a contaminant of a wide variety of foods including cereals, green coffee, spices, nuts, dried fruits, beer, wine, grapes, and grape juice (Ghali et al., 2009). Many countries and international organizations have regulated the OTA content in several commodities.

\section{Materials and Methods}

\section{Sample collected}

Total of 90 nut samples (almonds, $\mathrm{Br}$. Almonds, hazelnuts, cashews, walnuts and peanut) were collected from Tripoli, Libya during 2013.The sample was stored in polyethylene bags at $-18{ }^{\mathrm{O}} \mathrm{C}$ for determination of aflatoxins.

\section{Extraction of aflatoxins (AFs) nuts according to CB method of AOAC (2007) as follow}

Fifty grams of each ground samples were weighed into $500 \mathrm{ml}$ Erlenmeyer flask containing $25 \mathrm{~g}$ diatomaceous earth, $250 \mathrm{ml}$ chloroform and $25 \mathrm{ml}$ distilled water. The mixture was shacked with a horizontal shaker for $30 \mathrm{~min}$. The extract was filtered thro $\mu \mathrm{gh}$ Whatman No.4 filter paper. The first $50 \mathrm{ml}$ of extract was collected and transferred for clean up using silica gel column.

Clean up: Chromatographic columns were prepared by initially packing anhydrous sodium sulphate $(5 \mathrm{~g})$ into glass tube $(22$ x300 $\mathrm{mm})$ with plug of glass wool. Chloroform was added to $10 \mathrm{~g}$ silica for column to create slurry, which was added to the chromatographic column. The stopcock was opened to allow the silica gel packing to settle, while the excess chloroform was drained. During draining, another $10 \mathrm{~g}$ anhydrous sodium sulphate was added to the 
top of silica gel to prevent column from drying. A portion of filtrate $(50 \mathrm{ml})$ was loaded to the column and allowed to flow at a rate of one drop/second. Then, $150 \mathrm{ml} \mathrm{n}$ hexane followed by $150 \mathrm{ml}$ diethyl ether was passed through and discarded. Subsequently, aflatoxins were eluted with $150 \mathrm{ml}$ chloroform: methanol (97: 3, v/v) into 250 Erlenmeyer flask and then was evaporated to dryness on steam bath. The residue was quantitatively transferred to a small vial with chloroform and evaporated to dryness on steam bath under nitrogen and reserved for TLC and HPLC analysis.

\section{Determination of aflatoxins by HPLC}

\section{Derivatization}

The derivatives of tested samples and standards were done as follow: Tow hundred $\mu l$ hexane were added to the clean up dry film of standard and tested samples followed by $50 \mu \mathrm{l}$ Trifluroacetic acid (TFA), cap vial, and their mixed by vortex vigorously for $30 \mathrm{~s}$. The mixture was left to stand for $5 \mathrm{~min}$. To the mixture $450 \mathrm{ml}$ water- acetonitril $(9+1$ $\mathrm{v} / \mathrm{v}$ ) by pipet were added and mixed well by vortex for $30 \mathrm{~s}$, and the mixture was left to stand for $10 \mathrm{~min}$. to form two separate layers. The lower aqueous layer was used for HPLC analysis (AOAC, 2007).

\section{Apparatus}

High performance liquid chromatography (HPLC) was used to aflatoxins determination. A mobile phase consists of water: acetonitril: Methanol (240:120:40). The system equipped with (Waters 600) delivery system. HPLC column a reverse phase analytical column packed with C18 material (Spherisorb $5 \mu \mathrm{m}$ ODS2, $15 \mathrm{~cm} \times 4.6 \mathrm{~nm})$. The detection was performed using the fluorescence detector was operated at an excitation wave length of $360 \mathrm{~nm}$ and an emission wave length of 440 nm. The separation was performed at ambient temperature at a flow rate of $1.0 \mathrm{ml} / \mathrm{min}$,. Data were integrated and recorded using a Millennium Chromatography. Manger Software 2010 (Waters, Milford MA 01757)

\section{Quantization}

The mixed solutions of standard as well as sample extract after derivatisation were filtered thro $\mu$ gh a $0.22 \mu \mathrm{m}$ membrane filter and loaded $(50 \mu \mathrm{l})$ into a $200 \mu \mathrm{l}$ injection loop. The elution order of the four aflatoxins was $\mathrm{G}_{2}, \mathrm{~B}_{2}, \mathrm{G}_{2 \mathrm{a}}\left(\mathrm{G}_{1}\right.$ derivative $), \mathrm{B}_{2 \mathrm{a}}\left(\mathrm{B}_{1}\right.$ derivative).AFs contents in samples were calculated from chromatographic peak areas using the standard curve.

\section{Detection and determination of ochratoxinA}

\section{Extraction}

Fifty grams of nuts were put into high speed blender; $25 \mathrm{ml}$ phosphoric acid (0.1M) and $250 \mathrm{ml}$ chloroform were added and blended for $3 \mathrm{~min}$. at medium speed. Ten gram diatomaceous earth were added just before the end blending time then filtered through Whatman No.4 filter paper and $50 \mathrm{ml}$ portion were collected, transferred to separator funnel, $10 \mathrm{ml}$ sodium bicarbonate $(3 \%)$ were added and shacked gently, then the upper phase was collected for column separation.

\section{Clean up}

A Sep-Pak C18 Column was placed on vacuum monifold ports, column prewashed twice with $2 \mathrm{ml}$ methanol, $2 \mathrm{ml}$ water, and 2 $\mathrm{ml}$ sodium bicarbonate $(3 \%)$. Five $\mathrm{ml}$ bicarbonate extract were added to the $\mathrm{C} 18$ column, followed by $2 \mathrm{ml}$ phosphoric acid $(0.1 \mathrm{M})$ and $2 \mathrm{ml}$ water, and washings were discarded. OTA was eluted with $8 \mathrm{ml}$ ethyl acetate: methanol: acetic acid (95: 5: 0.5 
$\mathrm{v} / \mathrm{v} / \mathrm{v})$. The elute was collected in vial containing $2 \mathrm{ml}$ water and the elute was shacked with tube shaking machine (vortex genie) to mix the two phases. Pipette OTA extract (upper phase) to $7 \mathrm{ml}$ screw- cap vial. Rinse remaining upper phase from tube with 2 $\mathrm{x} 1 \mathrm{ml}$ ethyl acetate and add to OTA. Evaporate extract just to dryness on steam bath under nitrogen for subsequent HPLC analyses (AOAC, 2007).

\section{Determination}

\section{Determination of OTA by HPLC}

The fore-mentioned columns elutes were dissolve in $500 \mu \mathrm{l}$ mobile phase consists of acetonitrile: water: acetic acid (99:99:2) and filter thro $\mu$ gh $0.45 \mu \mathrm{m}$ microfilter into $5 \mathrm{ml}$ screw cap vial for subsequent HPLC analyses. High performance liquid chromatography (HPLC) was used to ochratoxins A Determination. The system equipped with (Waters 600) delivery system. HPLC column a reverse phase analytical column packed with C18 material (Spherisorb $5 \mu \mathrm{m}$ ODS2, $15 \mathrm{~cm} \times 4.6 \mathrm{~nm})$. The detection was performed using the fluorescence detector was operated at an excitation wave length of $330 \mathrm{~nm}$ and an emission wave length of 460 $\mathrm{nm}$. The separation was performed at ambient temperature at a flow rate of $1.0 \mathrm{ml} / \mathrm{min}$. Data were integrated and recorded using a Millennium Chromatography [Manger Software 2010 (Waters, Milford MA 01757)].

\section{Quantization}

Calculated from chromatographic peak areas using the standard curve.

\section{Results and Discussion}

\section{Natural occurrence of aflatoxin}

The obtained results of table 1 and figures 1,2 and 3 showed the natural occurrence of aflatoxin B1, B2, G1 and G2 in almonds, Brazilian almonds, Hazelnuts, cashews, walunts and peanuts samples collected from local market in Tripoli. The percentages of positive nuts sample (Almonds, Brazilian Almonds, Hazelunts, Cashews, Walnunts and Peanuts) were contaminants with aflatoxins 33.3, 40.0, 20.0, 13.3, 26.6 and 53.3\%, also the concentrations of aflatoxin B1 were ranged between (0.9-5.3,1.4- 7.8, 1.2 -5.4, $2.1-3.4, \quad 1.6-7.8$ and $2.4-10.9 \mu \mathrm{g} / \mathrm{kg}$, respectively. Aflatoxin $\mathrm{B} 2$ were found in $\mathrm{Br}$. Almonds ranged from $(2.2-3.5 \mu \mathrm{g} / \mathrm{kg})$ and in peanut $(7.6-8.4 \mu \mathrm{g} / \mathrm{kg})$.

Higher values of contamination with aflatoxin B1 and B2 were observed in peanut. These results may be attributed to type of cultivation or poor transportation, handling and storage condition of nuts. Storage, whether in the farm, on in manufacturing premises or in the grocery store, is considered one of the most critical post-harvest phases in food handling. Inappropriate environmental conditions, improper packaging or spoiled foodstuffs can cause mycotoxin contamination during this stage (FAO/WHO/UNEP, 1999). Aflatoxins were detected in $90 \%$ of hazelnut samples $(25-175 \mu \mathrm{g} / \mathrm{kg})$ and $75 \%$ of walnut samples (15-25 $\mu \mathrm{g} / \mathrm{kg}$ ). Jimenez et al., (1991) reported moulds and mycotoxins in almonds, peanuts, hazelnut and pistachio nuts and detected aflatoxins at up to $95 \mu \mathrm{g} / \mathrm{kg}$ in the samples.

According to many reports, peanuts are the main susceptible products for aflatoxin contamination. Tree nuts such as almonds, walnuts, and pistachios may be contaminated with aflatoxin, though at lower levels than for cottonseed and corn; however, the problem is very significant to producers because: (1) the crop has a high unit value, and (2) much of the crop is sold to European markets that enforce limits significantly lower than those in some countries (Shephard, 2003). For over 
all sanitary precaution, the European Union has enacted in 1998, very severe aflatoxin tolerance standards of $2 \mu \mathrm{g} / \mathrm{kg}$ AFB1 and 4 $\mu \mathrm{g} / \mathrm{kg}$ total aflatoxins for nuts and cereals for human consumption and this has come into effect from January, 2001. Consumers in the developed world are well aware of the carcinogenic effect of aflatoxins and will thus stay away from a product that has aflatoxin beyond the acceptance level. Exports of agricultural products particularly groundnuts and other oilseeds from developing countries have dropped considerately in recent years resulting in major economic losses to producing countries as a result of this restriction. According to the World Bank estimate, the policy change by the European Union will reduce by $64 \%$, imports of cereals, dried fruits, oil seeds and nuts from nine African countries namely Chad, Egypt, Gambia, Mali, Nigeria, Senegal, South Africa, Sudan and Zimbabwe and this will cost African countries about US $\$ 670$ million in trade per year. However, the new rule of the EU has been criticized as being too stringent. There is the need for mycotoxin surveillance because of its wide occurrence in contaminated commodities (Negedu et al., 2011).

Table.1 Survey of aflatoxins in nuts collected from Tripoli, Libya during (2013)

\begin{tabular}{|c|c|c|c|c|c|c|c|}
\hline \multirow{3}{*}{ Kind of nuts } & \multirow{3}{*}{$\begin{array}{c}\text { No. of } \\
\text { samples }\end{array}$} & \multirow{3}{*}{$\begin{array}{c}\text { No. of } \\
\text { positive } \\
\text { samples }\end{array}$} & \multirow{3}{*}{$\begin{array}{c}\text { Percentage } \\
\text { of positive } \\
\text { samples }\end{array}$} & \multicolumn{4}{|c|}{$\begin{array}{c}* \text { Concentration of Aflatoxins } \\
\mu \mathrm{g} / \mathrm{kg}\end{array}$} \\
\hline & & & & \multicolumn{2}{|c|}{ AFB1 } & \multicolumn{2}{|c|}{ AFB2 } \\
\hline & & & & Min & Max & Min & Max \\
\hline Almonds & 15 & 5 & 33.3 & 0.9 & 5.3 & ND & ND \\
\hline Br.Almonds & 15 & 6 & 40.0 & 1.4 & 7.8 & 2.2 & 3.5 \\
\hline Hazelnuts & 15 & 3 & 20.0 & 1.2 & 5.4 & 1.5 & ND \\
\hline Cashews & 15 & 2 & 13.3 & 2.1 & 3.4 & ND & ND \\
\hline Walnuts & 15 & 4 & 26.6 & 1.6 & 7.8 & ND & ND \\
\hline Peanuts & 15 & 8 & 53.3 & 2.4 & 10.9 & 7.6 & 8.4 \\
\hline
\end{tabular}

ND: Not Detectable.

* aflatoxins G1 and G2 not detectable

Figure.1 The percentages of positive nuts sample

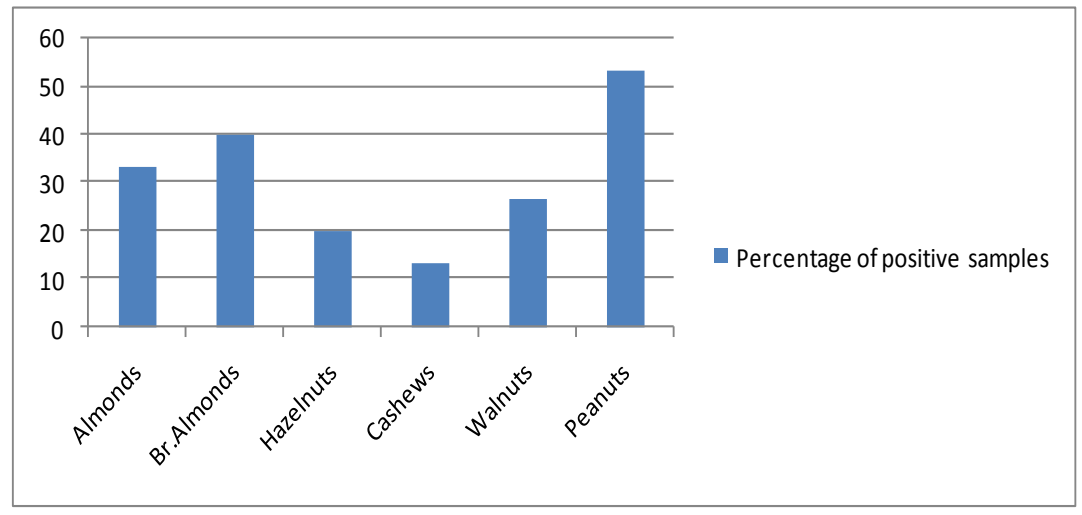


Figure.2 The minimum and maximum concentrations of aflatoxin B1 $(\mu \mathrm{g} / \mathrm{kg})$

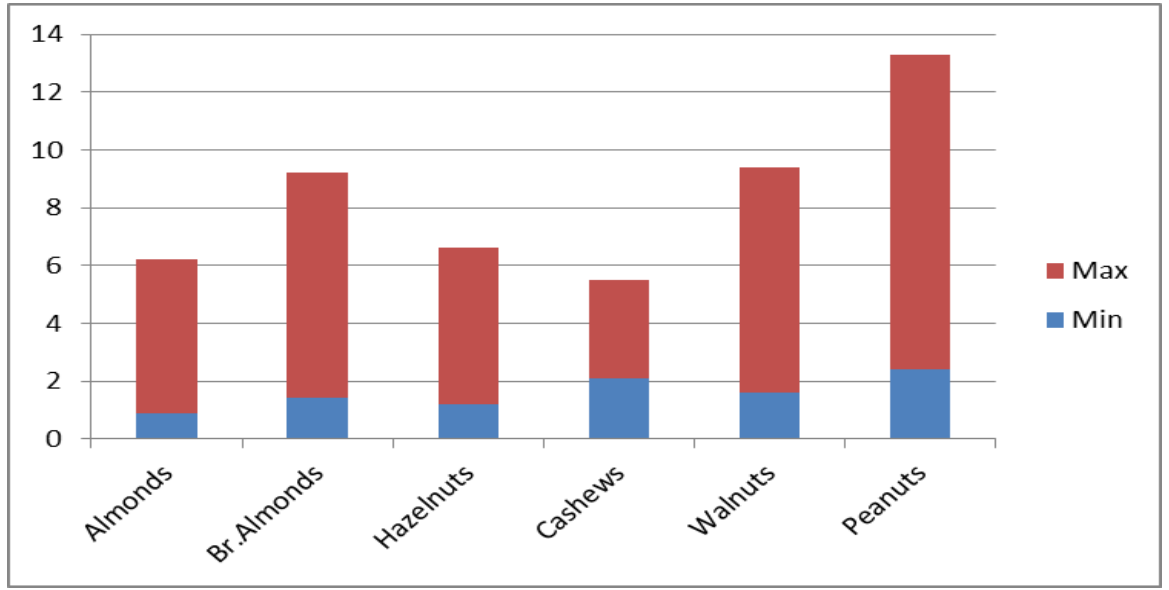

Figure.3 The minimum and maximum concentrations of aflatoxin B2 $(\mu \mathrm{g} / \mathrm{kg})$

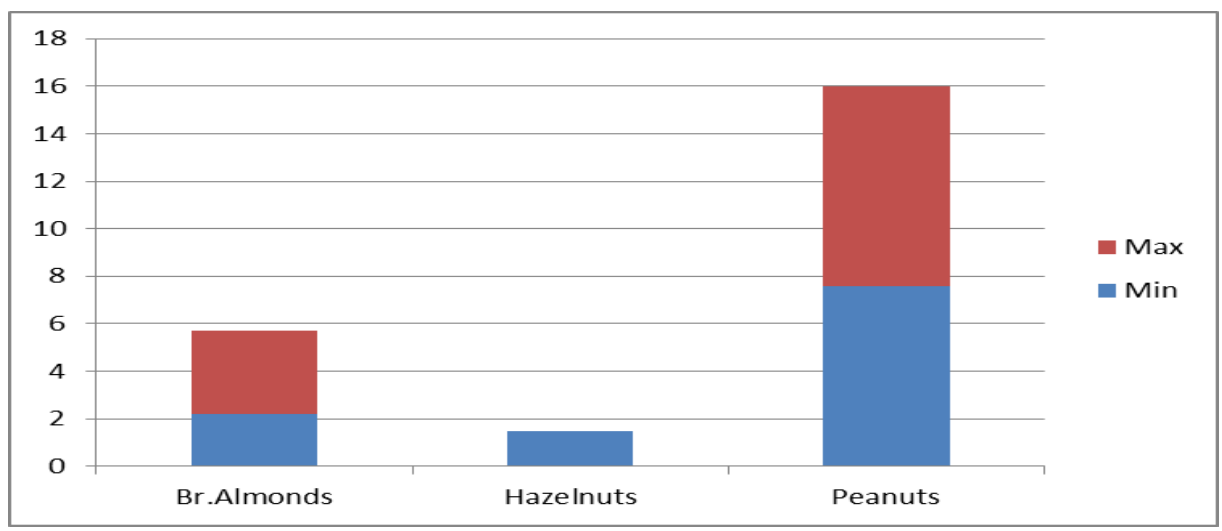

Table.2 Survey of ochratoxin A in nuts collected from Tripoli, Libya during, 2013

\begin{tabular}{|c|c|c|c|c|c|}
\hline \multirow{2}{*}{ Kind of nut } & \multirow{2}{*}{$\begin{array}{c}\text { No. of } \\
\text { samples }\end{array}$} & \multirow{2}{*}{$\begin{array}{c}\text { No.of } \\
\text { positive } \\
\text { samples }\end{array}$} & \multirow{2}{*}{$\begin{array}{c}\text { Percentage } \\
\text { of positive } \\
\text { samples }\end{array}$} & \multicolumn{2}{|c|}{$\begin{array}{c}\text { Ochratoxin A } \\
\text { concentration } \boldsymbol{\mu g} / \mathbf{k g}\end{array}$} \\
\cline { 5 - 6 } & & & Min & Max \\
\hline Almonds & 15 & ND & 26.6 & ND & ND \\
\hline Brazilian Almonds & 15 & 5 & 33.3 & 3.5 & 5.0 \\
\hline Hazelnuts & 15 & 2 & 13.3 & 1.5 & 2.2 \\
\hline Cashews & 15 & 3 & 20.0 & 1.2 & 3.7 \\
\hline Walnuts & 15 & 2 & 13.3 & 1.3 & 2.5 \\
\hline Peanuts & 15 & 5 & 33.3 & 4.0 & 6.5 \\
\hline
\end{tabular}


Figure.4 The percentages of positive nuts sample

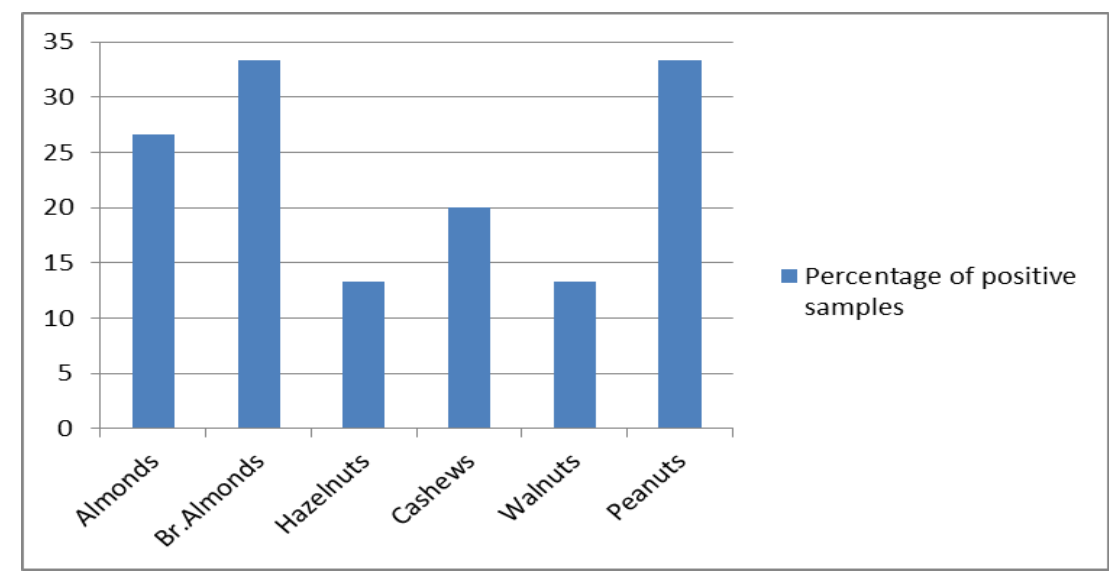

Figure.5 The minimum and maximum concentrations of ochratoxin $\mathrm{A}(\mu \mathrm{g} / \mathrm{kg})$

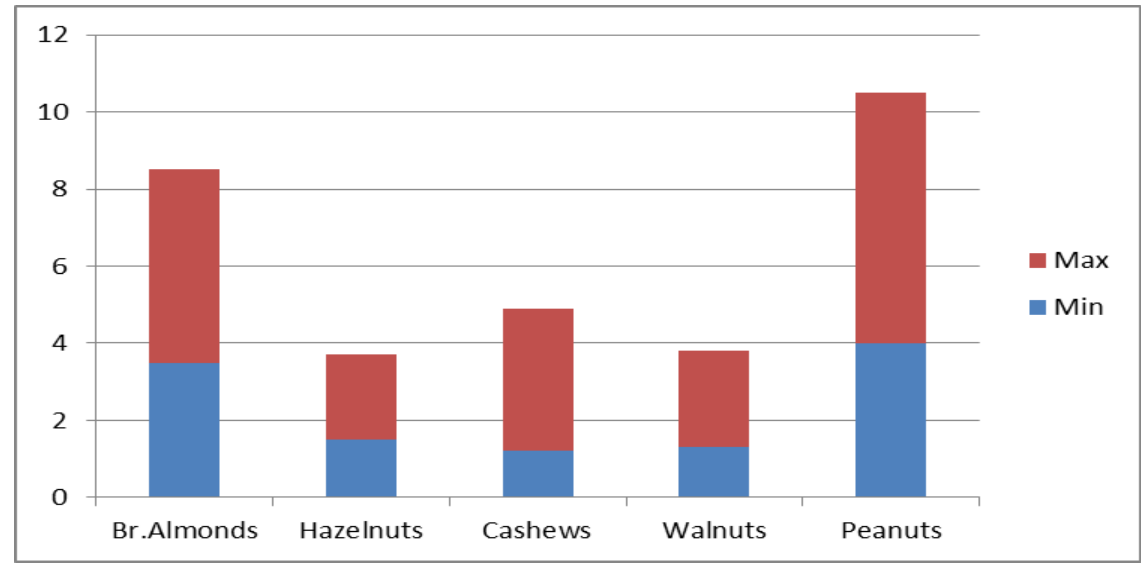

\section{Natural occurrence of ochratoxin A}

The obtained results of table 2 and figures 4 and 5 showed the natural occurrence of ochratoxin A in nuts samples collected from local market in Tripoli. The percentages of positive nuts sample (Almonds, Brazilian Almonds, Hazelnuts, Cashews, walnuts and peanuts) were contaminants with ochratoxin A 26.6,33.3, 13.3,20.0, 13.3and $33.3 \%$, respectively, also the concentrations were ranged between 3.5-5.0, 1.5- 2.2, 1.2 -3.7, 1.32.5, and 4.0-6.5 $\mu \mathrm{g} / \mathrm{kg}$ for Brazilian Almonds, Hazelnuts, Cashews, walnuts and peanuts. However almonds free of ochratoxin A.

Several studies have reported the incidence of black aspergilla in pistachios and other tree nuts. A. niger was found in $42 \%$ of nuts samples including pistachios, almonds, walnuts and Brazilian nuts (Bayman et al., 2002). They have been recently associated with the presence of ochratoxin A (OTA) in grapes and their derivatives (Battilani et al., 2003). The main species involved in OTA contamination is Aspergillus carbonarius and a low percentage of isolates of the closely related species in A. niger aggregate (Belli et al., 2004).

\section{References}

Alvarez, L., Gil, A.G., Ezpeleta, O., Garcia-Jalon, J.A., Lopez de Cerain, A. 2004. Immunotoxic effects of ochratoxin $\mathrm{A}$ in wistar rats after oral administration. Food Chem. Toxicol., 42: 825-834. 
AOAC. 2007. Official Method of Analysis of AOAC International, 18th ed. AOAC Int. Gaithersburg, MD.USA.

Battilani, P., Giorni, P., Pietri, A. 2003. Epidemiology of toxin-producing fungi and ochratoxin A occurrence in grape. Eur. J. Plant Pathol., 109: 715-722.

Bayman, P., Baker, J.L., Mahoney, E.N. 2002. Aspergillus on tree nuts: incidence and associations. Mycopathologia, 155: 161169.

Belli, N., Pardo, E., Marin, S., Farre, G., Ramos, A.J., Sanchis, V. 2004. Occurrence of ochratoxin A and toxigenic potential of fungal isolates from Spanish grapes. J. Sci. Food Agric., 84; 541-546.

Bellí, N., Ramos, A.J., Coronas, I., Sanchis, V., Marín, S. 2005. Aspergillus carbonarius growth and ochratoxin A production on a synthetic grape medium in relation to environmental factors. J. Appl. Microbiol., 98: 839-844.

Chulze, S.N., Magnoli, C.E., Dalcero, A.M. 2006. Occurrence of ochratoxin A in wine and ochratoxigenic mycoflora in grapes and dried vine fruits in South America. Int. J. Food Microbiol., 111: 5-9.

Ghali, R., Hmaissia-Khlifa, K., Ghorbel, H., Maaroufi, K., Hedili, A. 2009. HPLC determination of ochratoxin $\mathrm{A}$ in high consumption Tunisian foods. Food Control, 20: 716-720.

Gonzalez, L., Juan, C., Soriano, J.M., Molto, J.C., Manes, J. 2006. Occurrence and daily intake of ochratoxin A of organic and nonorganic rice and rice products. Int. J. Food Microbiol., 107: 223-227.

Grajewski, J., Blajet-Kosicka, A., Twaruzek, M., Kosicki, R. 2012. Occurrence of mycotoxins in polish animal feed in years 2006-2009. J. Animal Physiol. Animal Nutri., 96: 870-877.
Hult, K., Plestina, R., habazin-Novak, V., Radic, B., Ceovic, S. 1982. Ochratoxin A in human blood and Balkan endemic nephropathy. Arch. Toxicol., 51: 313-321.

International Agency for Research on Cancer, IARC. 1993. Monographs on the evaluation of carcinogenic risks to humans, 56: 257263.

Jimenez, M., Mateo, R., Querol, A., Huerta, T., Hernandez, E. 1991. Mycotoxins and mycotoxigenic moulds in nuts and sunflower seeds for human consumption. Mycopathologia, 115: 121-127.

Kabak, B. 2009. The fate of mycotoxins during thermal food processing. J. Sci. Food Agric., 89: 549-554.

Makun, H.A., Gbodi, T.A., Akanya, H.O., Salako, E.A., Ogbadu, G.H. 2009. Fungi and some mycotoxins found in mouldy Sorghum in Niger State, Nigeria. World J. Agri. Sci., 5: 5-17.

Moss, M.O. 1998. Recent studies of mycotoxins. J. Appl. Microbiol., 84: 62-76.

Negedu, A., Atawodi, S.E., Ameh, J.B., Umoh, V.J., and Tanko, H.Y. 2011. Economicand Health Perspectives of Mycotoxins: A Review. Continental J. Biomed. Sci., 5(1): 5-26.

Nguyen, K.T.N., Ryu, D. 2014. Concentration of ochratoxin A in breakfast cereals and snacks consumed in the United States. Food Control, 40: 140-144.

Pittet, A. 1998. Natural occurrence of mycotoxins in foods and feeds - an updated review. Revue. Med. Vet., 149: 479-492.

Prelle, A., Spadaro, D., Garibaldi, A., Gullino, M. 2012. Aflatoxin monitoring in Italian hazelnut products by LCeMS. Food Addit. Contam. Part B, 5: 279-285.

Shephard, G.S. 2003. Aflatoxin and Food Safety: Recent African Perspectives. J. Toxicol., 22(2-3): 267-286.

\section{How to cite this article:}

Essawet, N., H. Abushahma, S. Inbaia1, A. Najii and Amra, H.A. 2017. Natural Incidence of Aflatoxins and Ochratoxin A Nuts Collected from Local Market in Tripoli. Int.J.Curr.Microbiol.App.Sci. 6(3): 1479-1486. doi: https://doi.org/10.20546/ijcmas.2017.603.170 